\title{
Nematophagous Pleurotus Species Consume Some Nematode Species but Are Themselves Consumed by Others
}

\author{
Maria Marlin ${ }^{1, *}$, Avery Wolf ${ }^{1}$, Maryam Alomran ${ }^{2,3}$, Lynn Carta ${ }^{4}\left(\mathbb{C}\right.$ and George Newcombe ${ }^{1}[\mathbb{C}$ \\ 1 College of Natural Resources, Department of Forest, Rangeland, and Fire Sciences, University of Idaho, \\ Moscow, ID 83844, USA; wolf1613@vandals.uidaho.edu (A.W.); georgen@uidaho.edu (G.N.) \\ 2 College of Agricultural and Life Sciences, Department of Plant Sciences, University of Idaho, Moscow, \\ ID 83844, USA; alom4874@vandals.uidaho.edu \\ 3 College of Science, Department of Biology, Princess Nourah bint Abdulrahman University, Riyadh 11671, \\ Saudi Arabia \\ 4 Mycology and Nematology Genetic Diversity and Biology Laboratory, USDA-ARS, Beltsville, MD 20705, \\ USA; Lynn.Carta@ars.usda.gov \\ * Correspondence: maria.ann.marlin@gmail.com; Tel.: +1-484-894-2638
}

Received: 2 April 2019; Accepted: 8 May 2019; Published: 10 May 2019

\begin{abstract}
Pleurotus species are said to be nematophagous because they paralyze and consume some bacterial-feeding nematodes. It has never been clear whether that means all nematodes. Here we tested thirteen bacterial-feeding nematode species: seven of family Rhabditidae, three of Cephalobidae (one with three populations), two of Panagrolaimidae, and one of Diplogastridae. Nematodes interacted on water agar with toxin-producing isolates of Pleurotus pulmonarius (Fr.) Quél. and Pleurotus ostreatus (Jacq.) P. Kumm. Of the thirteen species, nine were susceptible to P. pulmonarius (all individuals were paralyzed) but four (four populations of two cephalobid species, one rhabditid, and one panagrolaimid) survived exposure to P. pulmonarius. The resistant four species not only survived but multiplied their numbers by consuming P. pulmonarius. A similar trend was observed with nematodes interacting with P. ostreatus; however, six species were resistant to P. ostreatus. Interestingly, four of these six species were susceptible to P. pulmonarius, and interactions overall were differential. Pleurotus species are nematophagous toward some nematodes but are also consumed by others in three of the four families assayed. Species-specific interactions point to the need for studies of the host ranges of both "nematophagous" fungi and "fungivorous" nematodes, especially if they are to be used for biological control.
\end{abstract}

Keywords: host range; soil; Rhabditidae; Cephalobidae; toxin; fungivorous

\section{Introduction}

Nematodes are roundworms, generally microscopic, that include parasites of animals and plants as well as beneficial species. Killing parasites has become problematic as resistance has developed to many previously useful therapeutic chemicals [1]. Therefore, biocontrol agents of nematodes may provide less toxic and more sustainable control with more varied and complex mechanisms that are harder for nematodes to resist.

Nematophagy implies the consumption of nematodes. The predatory consumer could be another invertebrate, such as a mite [2], or bacteria, such as Bacillus thuringiensis employing a toxin [3] or Chryseobacterium nematophagum producing enzymes [4], or a fungus. However, how do fungi manage this? Reviews of the subject frequently focus on the trapping and feeding mechanisms employed by nematophagous fungi [5]. Others focus on the diversity [6], and phylogenetic 
relationships [7] of those 700 or so fungal species discovered thus far to be nematophagous. Traps, adhesive spores, and specialized structures have been reported along with toxins. Nematophagous fungi are also sometimes called carnivores because they consume the "meat" of the trapped or toxin-stunned nematodes [8]. Some are termed predators whereas others are endo-parasitoids. The most recent proposal for mechanism-based classification of nematophagous fungi is for five groups: "nematode-trapping/predators, opportunistic or ovicidal, endoparasites, toxin-producing fungi and producers of special attack devices" [9].

Few studies address the topic of host range in nematophagous fungi; host ranges of toxin-producing fungi appear to be particularly neglected. The host range of a nematophagous fungus should comprise all susceptible species of nematodes attacked and consumed by that fungus. Experimental determination of the host range would require testing of many nematode species, but all too often, only a single or a few species were tested. There are exceptions, where numerous nematode species were used to determine the host range. For example, Tzean \& Liou (1993) [10] employed 11 different nematode species across multiple feeding guilds to determine that nematophagous Hyphoderma species have specific nematode host ranges; some nematodes were not affected at all by the fungus. However, in the absence of experimental determinations, host range may be assumed to encompass more species of nematodes than is actually the case. In the case of Pleurotus ostreatus (Jacq.) P. Kumm., its host range has been assumed to be broad since its toxin, trans-2-decenoic acid, derived from linoleic acid, has even been said to affect "not only nematodes, but also insects and other fungi" [9].

We first began thinking about the host range of nematophagous fungi when reading two research articles on nematode feeding habits in which mention was made of Pleurotus ostreatus as a good host for fungal-feeding Filenchus species. [11,12]. Interactions with P. ostreatus varied based on nematode species. For example, Filenchus misellus was capable of avoiding paralysis and feeding on P. ostreatus hyphae, while Aphelenchus avenae was always trapped and consumed by the fungus. However, the two media employed in this research did not include water agar, on which nematophagy by Pleurotus is normally assayed. Instead, P. ostreatus was grown on soil and potato dextrose agar (PDA), even though Barron \& Thorn (1987) [13] had found that the Pleurotus toxin is not as effective when grown on PDA; the toxin is most potent when the fungus is grown on a nutrient-limited media such as water agar. The soil used in the Filenchus assay was amended with soybean, a source of nitrogen, so it is again possible the fungal toxin was not at its maximum potency. Since the nematodes had not likely been exposed to the toxin in its most potent form, definitive inferences could not be drawn. Okada et al. (2005b) [14] discovered that Tylencholaimus parvus, a fungivorous nematode species, can survive exposure to both Pleurotus pulmonarius (Fr.) Quél. and Pleurotus ostreatus when the fungus is grown on water agar. Additionally, the nematode could consume the Pleurotus hyphae. Like their prior study [11], Aphelenchus avenae (control) was consumed by both Pleurotus species on the water agar. This study opened the door to the idea that Pleurotus species have specific host ranges of nematodes that they are capable of consuming.

Toxins are deleterious chemical compounds that are produced by, and that enhance the fitness of, living organisms. Typically, toxins are effective against some, but not all, other organisms. Species of white-rot fungi in Pleurotus possess a unique mechanism of toxin-assisted nematode trapping, which has been demonstrated on both water agar and wood $[13,15]$. Multiple studies have confirmed that bacterial-feeding nematodes belonging to various families in the order Rhabditida are susceptible to toxins produced by Pleurotus species [13,16-18]. When grown in a nitrogen-poor environment like wood, P. ostreatus will produce a toxin on aerial hyphae. Instead of diffusing into the environment, the toxin remains as a droplet on the hyphae. In this manner, the toxin remains undetected by the unfortunate nematode until contact is made; the nematode is promptly paralyzed by the toxin. Hyphae will then colonize the nematode, and eventually digest it [13]. In 1992, this toxin of P. ostreatus was characterized and named trans-2-decenedioic acid [18].

Other species of Pleurotus produce toxins with nematode-stunning activity similar to that of trans-2-decenedioic acid. Pleurotus pulmonarius, also used in our study of nematophagy, produces 
S-coriolic acid, linoleic acid, panisaldehyde, $p$-anisyl alcohol, 1-(4-methoxyphenyl)-1,2-propanediol, and 2-hydroxy-(4'-methoxy)-propiophenone [19]. We used the standard assay on water agar to determine the interactions of 13 species of nematodes with both P. pulmonarius and P. ostreatus. P. pulmonarius-resistant species were then further tested to confirm the fungus-feeding ability by pairing them with Rhizoctonia solani.

\section{Materials and Methods}

\subsection{Fungal Culture}

Pleurotus pulmonarius was isolated in early spring from a fresh basidiocarp collected on a Picea abies (L.) H. Karst. log in the University of Idaho Old Arboretum. Pleurotus ostreatus was isolated from mushrooms purchased at a local grocery store; the identity of this species was confirmed morphologically. Pleurotus ostreatus and Pleurotus pulmonarius are very similar, but P. pulmonarius grows on conifer wood in the Pacific Northwest and fruits in the spring [20]. Our Pleurotus isolates were transferred to oatmeal agar where cultures were allowed to grow at room temperature (approximately 21 degrees $\mathrm{C}$ ). For testing, 7-mm plugs were taken from growing cultures and transferred to plates containing $2 \%$ water agar (WA). These cultures were kept at room temperature and allowed to grow until the hyphae reached the edge of the plate (7 to 14 days). At that time, toxin production was noticeable.

\subsection{Nematode Culture}

Nematode feeding habits are only partially known. For example, "bacterial-feeding" nematodes can also graze on hyphae of at least some fungi. For our study, we selected 13 species of bacterial-feeding nematodes from four families, including Rhabditidae, known to include species susceptible to species of Pleurotus. All species of nematodes were grown and maintained on nematode growth media (NGM) agar with Escherichia coli OP50 as their food [21]. The following nematodes were then used in our Pleurotus-nematode interaction assay (described further below):

- $\quad$ Family Rhabditidae

Oscheius dolichura (Schneider) Sudhaus [LKC50], Oscheius myriophilus (Poinar) Sudhaus [DF5020], Oscheius tipulae (Lam and Webster) Sudhaus [LKC57], Caenorhabditis elegans (Maupas) Dougherty [N2], Mesorhabditis inarimensis (Meyl) Dougherty [LKC51], Poikilolaimus oxycercus (de Man) Sudhaus and Koch [LKC64], and Metarhabditis rainai (Carta and Osbrink) Sudhaus [LKC20]

- Family Cephalobidae

Zeldia punctata (Thorne) Thorne [PS1192], Acrobeloides varius Kim, Kim and Park [LKC52], Acrobeloides varius [PS1959], Acrobeloides varius [LKC27], and Acrobeloides sp. cf amurensis Truskova [PS1146]

- Family Panagrolaimidae

Panagrolaimus artyukhovskii Blinova \& Mishina [LKC44] and Panagrellus redivivus (Linnaeus) Thorne [PS1163]

- Family Diplogastridae

Pristionchus aerivorus (Cobb in Merrill \& Ford) Chitwood [LKC54]

To avoid redundancy, only one population of $A$. varius (LKC52) was used for the P. ostreatus assay. All three populations were tested with P. pulmonarius.

\subsection{Pleurotus-Nematode Interaction Assay}

Twenty active individuals, varying in age, of each nematode species were transferred to respective WA plates containing live mycelium of either P. pulmonarius or P. ostreatus. For the P. pulmonarius assay, we checked for paralysis due to toxin immediately after transfer and then every hour for the next six hours. The cultures were also checked one and two weeks after the nematode transfer for survival and 
reproduction of nematodes. Since we were only interested in the long-term survival of the nematode population, we checked $P$. ostreatus plates only after one week following the nematode transfer. For the purpose of this study, we defined resistance as survival of some individuals after contact with Pleurotus on water agar, and their subsequent ability to reproduce. Susceptible nematode species were defined as ones in which all 20 individuals perished during the first few hours on the water agar plate containing the Pleurotus mycelium.

\subsection{Phylogenetic Analysis}

DNA from nematode species was processed for the 18S rDNA marker [22] or taken from GenBank (Table 1). Taxa in Table 1 are phylogenetically disjunct in the tree containing only these taxa (Figure 1) so corresponding clades from a comprehensive large tree of $18 \mathrm{~S}$ sequences $[23,24]$ is referenced and shown. Sequences were aligned with Clustal W [25] and a Bayesian likelihood tree was constructed with a general time reversible (GTR) model and $10^{6}$ chain length in the MRBAYES plugin [26] in Geneious ver. 11.1.5 (Biomatters, Auckland, New Zealand) in Figure 1.

Table 1. Nematode cultures tested and represented in phylogenetic tree of Figure 1.

\begin{tabular}{|c|c|c|c|}
\hline Species & Culture Isolate & $\begin{array}{c}\text { GenBank } \\
\text { Accession/Isolate }\end{array}$ & $\begin{array}{l}\text { Clade in van Megen } \\
\text { et al., } 2009 \text { [23] }\end{array}$ \\
\hline Oscheius dolichura & LKC50 & $\begin{array}{l}\text { KP756940 } \\
\text { JU72 }\end{array}$ & 9A Rhabditomorpha \\
\hline Oscheius myriophilus & DF5020 & U81588 & $9 \mathrm{~A}$ \\
\hline Oscheius tipulae & LKC57 & $\begin{array}{c}\text { CEW1 } \\
\text { KP756939 }\end{array}$ & $9 \mathrm{~A}$ \\
\hline Caenorhabditis elegans & N2 & NR000054 & $9 \mathrm{~A}$ \\
\hline Mesorhabditis inarimensis & LKC51 & $90 \mathrm{~A} 3$ * MK636575 & $9 \mathrm{~A}$ \\
\hline Poikilolaimus oxycercus & LKC64 & 101A3* MK636576 & $9 \mathrm{~A}$ \\
\hline Metarhabditis rainai & LKC20 & $\begin{array}{c}\text { AF083008 } \\
\text { PS1191 }\end{array}$ & $9 \mathrm{~A}$ \\
\hline Pristionchus aerivorus & LKC54 & $90 \mathrm{C} 1 *$ MK636577 & 9A Diplogasteromorpha \\
\hline Panagrolaimus artyukhovskii & LKC44 & $90 \mathrm{E} 9 *$ MK636578 & $\begin{array}{c}10 \mathrm{~A} \\
\text { Panagrolaimomorpha }\end{array}$ \\
\hline Panagrellus redivivus & PS1163 & AF083007 & $10 \mathrm{~A}$ \\
\hline Zeldia punctata & PS1192 & U61760 & 11 Cephalobomorpha \\
\hline Acrobeloides amurensis & PS1146 & AF034391 & 11 \\
\hline Acrobeloides varius ** & LKC27 & $94 \mathrm{~A} 6 * \mathrm{MK} 636581$ & 11 \\
\hline Acrobeloides varius & LKC52 & $100 \mathrm{H} 3 *$ MK636579 & 11 \\
\hline Acrobeloides varius ${ }^{*}$ & PS1959 & $104 \mathrm{M} 16$ * MK636580 & 11 \\
\hline Plectus rhizophilus & PlecRhi1 & AY593928 & 6 (Outgroup) \\
\hline
\end{tabular}

${ }^{*}$ new sequence in this study. ${ }^{* *}$ only tested with Pleurotus pulmonarius. 


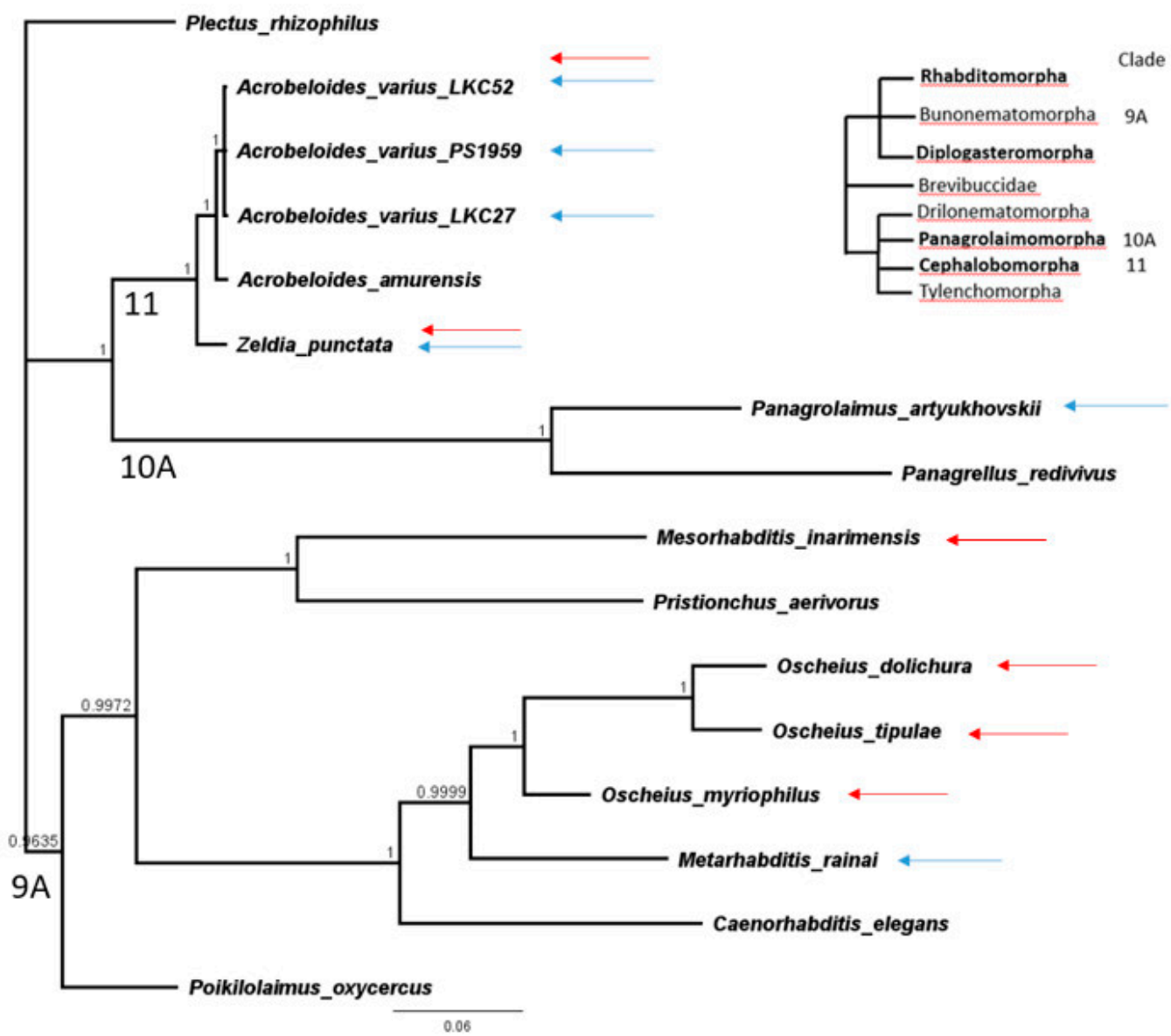

Figure 1. MRBAYES Bayesian likelihood phylogenetic tree based on a Clustal W alignment of $18 \mathrm{~S}$ rDNA sequences as implemented in Geneious ver. 11.1.5. Upper right schematic tree of van Megen et al., 2009 [23] provides phylogenetic context. Blue and red arrows indicate taxa resistant to P. pulmonarius and P. ostreatus, respectively.

\subsection{Fungal-Feeding Ability}

In order to confirm fungal-feeding ability of the P. pulmonarius-resistant nematodes, all of which were known as bacterial feeders prior to this study, approximately 10 mixed-stage juvenile nematodes were rinsed in sterile water from the bacterial plate and transferred using a pipette to PDA plates containing 7- to 10-day-old mycelial cultures of Rhizoctonia solani. They were then observed for consumption of the fungus and production of nematode eggs.

\section{Results}

\subsection{Pleurotus pulmonarius-Nematode Interaction Assay}

All 20 individuals of each of nine susceptible species were stunned or paralyzed by toxin in the first few hours after their introduction to Pleurotus plates. They were then consumed by Pleurotus hyphae. In the case of each of the six resistant populations of four species, a few individual nematodes appeared stunned during the first few hours. However, other individuals were not, and they went on to reproduce and feed on Pleurotus hyphae. Of the fifteen populations of thirteen species, nine were susceptible. Six of seven rhabditid species were susceptible: Oscheius dolichura (LKC50), Oscheius myriophilus (DF5020), Oscheius tipulae (LKC57), Caenorhabditis elegans (N2), Mesorhabditis inarimensis (LKC51), and Poikilolaimus oxycercus (LKC64). Only one of five populations of three cephalobid species was susceptible: Acrobeloides sp. cf amurensis (PS1146). One of two panagrolaimid species was 
susceptible: Panagrolaimus artyukhovskii (LKC44). Finally, the only species of diplogastrid assayed was susceptible to P. pulmonarius: Pristionchus aerivorus (LKC54).

Six populations representing four species of nematode were resistant to P. pulmonarius: four of five cephalobid populations comprising two species, one of seven rhabditids, and one of two panagrolaimid species.

\subsection{Pleurotus ostreatus-Nematode Interaction Assay}

Susceptible and resistant nematode interactions with P. ostreatus were also observed (Figure 2). Of the thirteen nematode species tested with $P$. ostreatus, seven species were susceptible. Three of the seven rhabditids were susceptible: Caenorhabditis elegans (N2), Poikilolaimus oxycercus (LKC64), and Metarhabditis rainai (PS1191). The only species of diplogastrid assayed, Pristionchus aerivorus (LKC54), was susceptible. Both panagrolaimid species were susceptible: Panagrolaimus artyukhovskii (LKC44) and Panagrellus redivivus (PS1163). Finally, similar to P. pulmonarius, only one of the three cephalobid species was susceptible: Acrobeloides amurensis (PS1146). Six species were resistant to P. ostreatus: four rhabditid species and two cephalobid species (Figure 1). All four rhabditid species resistant to P. ostreatus were susceptible to P. pulmonarius.

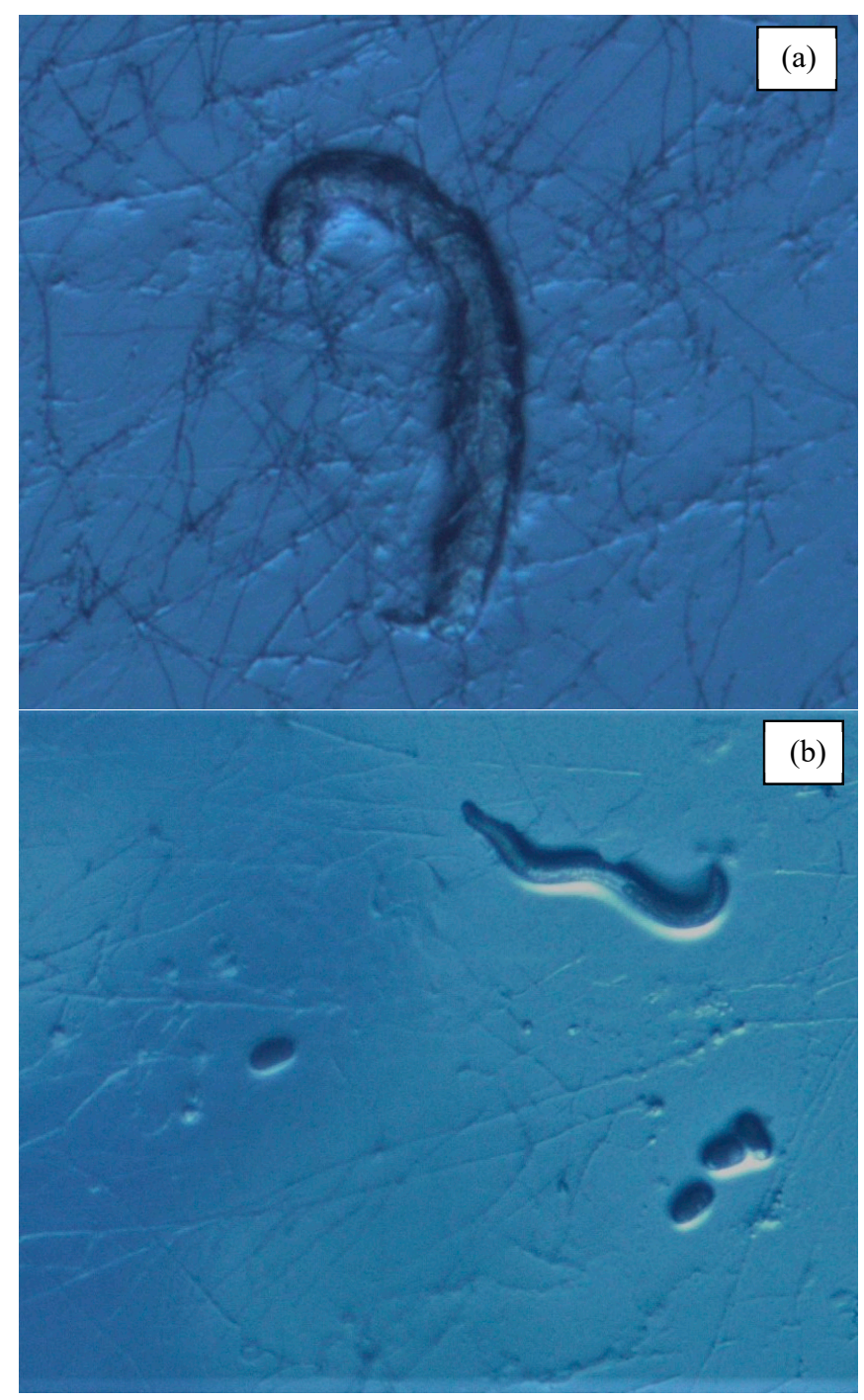

Figure 2. (a) Susceptible rhabditid species (Poikilolaimus oxycercus) being consumed by Pleurotus ostreatus hyphae. (b) Resistant cephalobid species, Zeldia punctata, interacting with Pleurotus ostreatus hyphae. Reproductive capability evidenced by the presence of eggs. 
It is evident from Figure 1 that Pleurotus resistance may have multiple origins among at least three families, including even the Rhabditidae, a family traditionally associated with Pleurotus susceptibility and which, here, was mostly susceptible to P. pulmonarius but surprisingly resistant to P. ostreatus. Resistance was especially common among species of Cephalobidae, including multiple isolates of one species, Acrobeloides varius, when confronted with P. pulmonarius.

\subsection{Phylogenetic Analyses}

The relative phylogenetic distance of the species and genera of nematodes is shown in trees of Figure 1. GenBank sequence accession numbers for some of the taxa generated for this work are listed in Table 1.

\subsection{Feeding Ability}

The ability of the P. pulmonarius-resistant, bacterial-feeding populations to multiply on another fungus, Rhizoctonia solani, was confirmed. This was not completely clear after two weeks. However, after three weeks of culturing on $R$. solani, all six of the Pleurotus-resistant nematode populations had produced eggs and multiplied their numbers.

\section{Discussion}

Our findings support earlier work [14] and provide evidence that Pleurotus species are more specialized within Nematoda than previously believed. In other words, nematophagous species of fungi have host ranges, a term applied by Barron (1978) [27], analogous to the host ranges of parasitic fungi [28], or the tree hosts of mycorrhizal fungi [29] or the range of mycorrhizal fungi parasitized by mycoheterotrophic plants [30]. The term applies not only to nematophagous fungi but also to fungivorous nematodes that might consume P. pulmonarius and R. solani, as here, but would likely be unable to consume others.

Our study adds a new layer to this complexity; differential interactions with the two Pleurotus species were observed. Previously [14], differential reactions had not been observed (Table 2). In other words, nematodes were either susceptible to both Pleurotus species or resistant to both Pleurotus species. However, in our study, this was not the case. As displayed in Table 3, some nematode species were resistant to $P$. ostreatus but susceptible to $P$. pulmonarius, and vice versa. All four sets (RS, SR, RR, and SS) of binary reaction (resistance or susceptibility) were seen. If six species of Pleurotus were tested, one might expect $2^{6}$, or 64 , unique sets of binary reaction.

Table 2. Nematode interactions with two species of Pleurotus grown on water agar from Okada et al. (2005b) [14]. One nematode species was susceptible to both Pleurotus species, while the other nematode species was resistant to both Pleurotus species. However, differential interactions (i.e., resistance to one Pleurotus species but susceptibility to the other), were not observed. $\mathrm{S}=$ susceptible, $\mathrm{R}=$ resistant.

\begin{tabular}{ccc}
\hline Nematode Species & Pleurotus pulmonarius & Pleurotus ostreatus \\
\hline Tylencholaimus parvus & $\mathrm{S}$ & $\mathrm{S}$ \\
Aphelenchus avenae & $\mathrm{R}$ & $\mathrm{R}$ \\
\hline
\end{tabular}


Table 3. Our results of bacterial-feeding nematode interactions with two species of Pleurotus grown on water agar. Nematode species revealed that the two species of Pleurotus were differential interactors with all four sets of interactions across the row: SR, SS, RS, and RR. S = susceptible, R = resistant.

\begin{tabular}{|c|c|c|c|}
\hline Species & Culture Isolate & Pleurotus pulmonarius & Pleurotus ostreatus \\
\hline Oscheius dolichura & LKC50 & S & $\mathrm{R}$ \\
\hline Oscheius myriophilus & DF5020 & S & $\mathrm{R}$ \\
\hline Oscheius tipulae & LKC57 & $S$ & $\mathrm{R}$ \\
\hline Caenorhabditis elegans & N2 & S & S \\
\hline Mesorhabditis inarimensis & LKC51 & S & $\mathrm{R}$ \\
\hline Poikilolaimus oxycercus & LKC64 & S & S \\
\hline Metarhabditis rainai & LKC20 & $\mathrm{R}$ & S \\
\hline Pristionchus aerivorus & LKC54 & $S$ & S \\
\hline Panagrolaimus artyukhovskii & LKC44 & $\mathrm{R}$ & S \\
\hline Panagrellus redivious & PS1163 & $\mathrm{S}$ & S \\
\hline Zeldia punctata & PS1192 & $\mathrm{R}$ & $\mathrm{R}$ \\
\hline Acrobeloides amurensis & PS1146 & $S$ & $S$ \\
\hline Acrobeloides varius ** & LKC27 & $\mathrm{R}$ & NA \\
\hline Acrobeloides varius & LKC52 & $\mathrm{R}$ & $\mathrm{R}$ \\
\hline Acrobeloides varius ** & PS1959 & $\mathrm{R}$ & NA \\
\hline
\end{tabular}

It seems likely that other toxin-producing nematophagous fungi, including other species in Pleurotaceae, might be similarly specialized if tested in the manner of this study. It is entirely possible that there are other nematophagous fungi that can attack the Pleurotus-resistant species of this study. Conversely, it seems possible that the Pleurotus-susceptible nematodes of this study would feed on fungi other than Pleurotus species. Each of Pleurotus pulmonarius and P. ostreatus was either the consumer or the consumed. It will be interesting to conduct further research to see whether this zero-sum game might be more widely operational among interacting fungi and nematodes.

In this study, only free-living bacterial-feeding nematodes were assayed because they had previously been used to show that Pleurotus species were nematophagous. Evidently, many bacterial-feeding nematodes can survive on fungus as the sole food source. An earlier study in which that was demonstrated involved a bacterial-feeding Chiloplacus species that was maintained on a fungal culture (i.e., Phoma [31]). Overall, research has focused little on bacterial-feeding nematodes' ability to consume fungi, indicating a gap in knowledge regarding feeding behavior and the potential host range of nematodes. Therefore, there may be a significantly higher number of nematodes that could be considered fungivorous. Future research on resistance or susceptibility to nematophagous Pleurotus might involve nematode-trophic groups or feeding guilds other than the bacterial-feeding group tested here. In particular, nematodes that are parasites of vertebrates and plants can be targeted by nematophagous fungi in biological control efforts [32].

Resistance to toxins, presumably the reported S-coriolic acid, linoleic acid, panisaldehyde, p-anisyl alcohol, 1-(4-methoxyphenyl)-1,2-propanediol,2-hydroxy-(4'-methoxy)-propiophenone, and trans-2-decenedioic acid allowed six populations of four nematode species to graze on P. pulmonarius and six nematode species to graze on P. ostreatus. We do note that some of the original individual nematodes in each of the resistant species died, and the reasons for their deaths were not determined. It could be that resistant nematode species are variable and some individuals are susceptible to Pleurotus toxins. On the other hand, a few individual deaths per resistant species could have nothing to do with Pleurotus toxins. Age-related resistance could factor into this observation; we used individuals of varying life stages in our assay. The mechanism for resistance to these toxins is also yet to be determined, but we can propose the following. First, the toxins may simply be lacking recognition or binding sites in resistant nematodes. This concept has been demonstrated in endoparastic nematophagous fungi, where differential trapping is noted. For example, Jansson et al. (1985) [33] showed that conidia of endoparasitic, nematophagous Meria coniospora can only attach and infect some species of nematodes. Their study agrees with prior work that suggests sialic acid on the nematode cuticle proves to be an 
important recognition and attachment factor for the fungus; reduction of sialic acid by the presence of sialic-acid specific lectin reduced conidial attachment [34].

A second hypothesis is that resistant nematodes may have evolved a mechanism to detoxify toxins before paralysis. Third, members of the microbiome of resistant nematodes could hypothetically offer protection from Pleurotus toxins. With respect to the third hypothesis, Dirksen et al. (2016) [35] found that three Pseudomonas species in the microbiome of C. elegans did exhibit antifungal activity towards pathogenic fungi. Thorough understanding of resistance will also have to integrate the fact that Pleurotus species also kill some species of bacteria [15].

The soil bacterium Burkholderia cepacia also produces a diffusible paralytic toxin that contributes to killing Caenorhabditis elegans [36]. Several strains were tested among a similar phylogenetic spectrum of bacterial-feeding nematodes as in this study. Zeldia punctata and Pristionchus pacificus were especially resistant among the tested nematodes to the toxic effects of B. cepacia [37], in line with their resistance to Pleurotus toxins in this work. Another cephalobid nematode, Acrobeloides maximus, was attracted to and fed on more bacterial genera than C. elegans. This was interpreted as an adaptation to a less enriched ecosystem [38] since cephalobid nematodes are early stage colonizers [39]. Perhaps similar resistance mechanisms are working in nematodes that have resistance to those bacterial toxins and to these fungal toxins.

More extensive testing of host ranges of both nematophagous fungi and fungivorous nematodes, as well as mechanisms for nematode resistance [40], should shed light on the physiology and ecology of interactions needed for targeted, integrated biocontrol. In fact, classical biocontrol agents have to be tested for host range prior to their introduction to an invaded range, to reduce the chance of non-target effects. This is relevant to Pleurotus since three nematophagous species (P. pulmonarius, P. ostreatus, and P. eryngii) have been considered as options for biocontrol of the pinewood nematode Bursaphelnchus xylophilus in its invaded range in east Asia [41]. Our results suggest that host range studies are needed to avoid undesirable, non-target effects. For example, soil-dwelling nematodes that vector mammalian pathogenic fungi [42] might be positively or negatively impacted by applications of nematophagous Pleurotus to pine forests affected by the pinewood nematode. More generally, the consequences of introductions of nematophagous fungi with undetermined host ranges could be both serious and unpredictable given the abundance of nematodes (i.e., famously four of every five animals on Earth) and their functional diversity in food webs [43].

\section{Conclusions}

Two species of nematophagous Pleurotus did not kill and consume all species of nematodes they encountered. We found that some species of nematodes were resistant to both species of Pleurotus, but others were resistant to one but susceptible to the other. Yet other species of nematode were susceptible to both species of Pleurotus. In each species-specific interaction, either all nematode individuals were killed or most lived and reproduced. Another inference from this study is that many bacterial-feeding nematodes could be fungivorus. Interactions among nematophagous fungi and nematodes could easily serve as a model for studying differential ecological interactions.

Author Contributions: Conceptualization, G.N.; Methodology, G.N. and M.M.; Phylogenetic Software, L.C.; Investigation, A.W. and M.A.; Resources, L.C. and G.N.; Data Curation, A.W.; Writing-Original Draft Preparation, M.M.; Writing-Review and Editing, G.N., L.C., and MM; Visualization, L.C. and M.M.; Supervision, M.M.

Funding: This research received no external funding but was supported by the Environmental Science program at the University of Idaho.

Acknowledgments: We thank Shiguang Li, MNGDBL, USDA-ARS Beltsville, MD for excellent technical assistance with cultures and many sequences of the nematodes used in this study. Mention of a trade name or commercial product in this publication is solely for the purpose of providing specific information and does not imply recommendation or endorsement by the U.S. Department of Agriculture (USDA). USDA is an equal opportunity provider and employer.

Conflicts of Interest: The authors declare no competing interests. 


\section{References}

1. Clarke, N.E.; Doi, S.A.R.; Wangdi, K.; Chen, Y.; Clements, A.C.A.; Nery, S.V. Efficacy of anthelminthic drugs and drug combinations against soil-transmitted helminths: A systematic review and network meta-analysis. Clin. Infect. Dis. 2019, 68, 96-105. [CrossRef]

2. Stirling, G.R.; Stirling, A.M.; Walter, D.E. The Mesostigmatid Mite Protogamasellus mica, an Effective Predator of Free-Living and Plant-Parasitic Nematodes. J. Nematol. 2017, 49, 327-333. [CrossRef] [PubMed]

3. Wei, J.-Z.; Hale, K.; Carta, L.; Platzer, E.; Wong, C.; Fang, S.-C.; Aroian, R.V. Bacillus thuringiensis crystal proteins that target nematodes. Proc. Acad. Sci. 2003, 100, 2760-2765. [CrossRef] [PubMed]

4. Page, A.P.; Roberts, M.; Félix, M.-A.; Pickard, D.; Page, A.; Weir, W. The golden death bacillus Chryseobacterium nematophagum is a novel matrix digesting pathogen of nematodes. BMC Boil. 2019, 17, 10. [CrossRef] [PubMed]

5. Nordbring-Hertz, B.; Jansson, H.B.; Tunlid, A. Nematophagous fungi. Enc. Life Sci. 2001. [CrossRef]

6. Zhang, K.-Q.; Hyde, K.D. Nematode-Trapping Fungi; Springer: Dordrecht, The Netherlands, 2014.

7. Thorn, R.G.; Moncalvo, J.-M.; Reddy, C.A.; Vilgalys, R. Phylogenetic Analyses and the Distribution of Nematophagy Support a Monophyletic Pleurotaceae within the Polyphyletic Pleurotoid-Lentinoid Fungi. Mycologia 2000, 92, 241. [CrossRef]

8. Thorn, R.G.; Barron, G.L. Carnivorous mushrooms. Science 1984, 224, 76-78. [CrossRef]

9. Soares, F.E.D.F.; Sufiate, B.L.; De Queiróz, J.H. Nematophagous fungi: Far beyond the endoparasite, predator and ovicidal groups. Agric. Resour. 2018, 52,1-8. [CrossRef]

10. Tzean, S.S. Nematophagous Resupinate Basidiomycetous Fungi. Phytopathology 1993, 83, 1015. [CrossRef]

11. Okada, H.; Kadota, I. Host status of 10 fungal isolates for two nematode species, Filenchus misellus and Aphelenchus avenae. Soil Boil. Biochem. 2003, 35, 1601-1607. [CrossRef]

12. Okada, H.; Harada, H.; Kadota, I. Fungal-feeding habits of six nematode isolates in the genus Filenchus. Soil Boil. Biochem. 2005, 37, 1113-1120. [CrossRef]

13. Barron, G.L.; Thorn, R.G. Destruction of nematodes by species of Pleurotus. Can. J. Bot. 1987, 65, 774-778. [CrossRef]

14. Okada, H.; Araki, M.; Tsukiboshi, T.; Harada, H. Characteristics of Tylencholaimus parvus (Nematoda: Dorylaimida) as a fungivorus nematode. Nematology 2005, 7, 843-849. [CrossRef]

15. Thorn, R.G.; Tsuneda, A. Interactions between various wood-decay fungi and bacteria: antibiosis, attack, lysis, or inhibition. Rep. Tottori Mycol. Inst. 1992, 30, 13-20. [CrossRef]

16. Larsen, M.; Nansen, P. Ability of the fungus Pleurotus pulmonarius to immobilize preparasitic nematode larvae. Res. Vet. Sci. 1991, 51, 246-249. [CrossRef]

17. Hibbett, D.S.; Thorn, R.G. Nematode-Trapping in Pleurotus tuberregium. Mycologia 1994, 86, 696. [CrossRef]

18. Kwok, O.C.H.; Plattner, R.; Weisleder, D.; Wicklow, D.T. A nematicidal toxin fromPleurotus ostreatus NRRL 3526. J. Chem. Ecol. 1992, 18, 127-136. [CrossRef]

19. Stadler, M.; Mayer, A.; Anke, H.; Sterner, O. Fatty Acids and Other Compounds with Nematicidal Activity from Cultures of Basidiomycetes. Planta Med. 1994, 60, 128-132. [CrossRef] [PubMed]

20. Trudell, S.; Ammirati, J. Mushrooms of the Pacific Northwest; Timber Press: Portland, OR, USA, 2009; pp. $134-135$.

21. Stiernagle, T. Maintenance of C. elegans. In C. elegans: A Practical Approach; Hope, I.A., Ed.; Oxford University Press: New York, NY, USA, 1999; pp. 51-68.

22. Carta, L.K.; Li, S. Improved $18 \mathrm{~S}$ small subunit rDNA primers for problematic nematode amplification. $J$. Nematol. 2018, 50, 533-542. [CrossRef]

23. Van Megen, H.; Elsen, S.V.D.; Holterman, M.; Karssen, G.; Mooyman, P.; Bongers, T.; Holovachov, O.; Bakker, J.; Helder, J. A phylogenetic tree of nematodes based on about 1200 full-length small subunit ribosomal DNA sequences. Nematology 2009, 11, 927-950.

24. Blaxter, M.; Koutsovoulos, K. The evolution of parasitism in Nematoda. Parasitology 2015, 142 (Suppl. S1), S26-S39. [CrossRef] [PubMed]

25. Thompson, J.D.; Higgins, D.G.; Gibson, T.J. CLUSTAL W: improving the sensitivity of progressive multiple sequence alignment through sequence weighting, position-specific gap penalties and weight matrix choice. Nucleic Acids Res. 1994, 22, 4673-4680. [CrossRef] [PubMed]

26. Huelsenbeck, J.P.; Ronquist, F.; Hall, B. MrBayes: A Program for the Bayesian Inference of Phylogeny; Software Manual; University of Rochester: Rochester, NY, USA, 2000. 
27. Barron, G.L. Nematophagous Fungi: Endoparasites of Rhabditis terricola. Microb. Ecol. 1978, 4, 157-163. [CrossRef] [PubMed]

28. Carnegie, A.J.; Lidbetter, J.R. Rapidly expanding host range for Puccinia psidii sensu lato in Australia. Australas. Australas. Plant Pathol. 2012, 41, 13-29. [CrossRef]

29. Marx, D.H. Tree host range and world distribution of the ectomycorrhizal fungus Pisolithus tinctorius. Can. J. Microbiol. 1977, 23, 217-223. [CrossRef] [PubMed]

30. Merckx, V.S.F.T.; Janssens, S.B.; Hynson, N.A.; Specht, C.D.; Bruns, T.D.; Smets, E.F. Mycoheterotrophic interactions are not limited to a narrow phylogenetic range of arbuscular mycorrhizal fungi. Mol. Ecol. 2012, 21, 1524-1532. [CrossRef]

31. Procter, D.L.C. Fecundity, reproductive effort, age-specific reproductive tactics and intrinsic rate of natural increase of a High Arctic nematode belonging to the genus Chiloplacus. Ecography 1986, 9, 104-108. [CrossRef]

32. Waller, P.; Faedo, M. The potential of nematophagous fungi to control the free-living stages of nematode parasites of sheep: screening studies. Vet. Parasitol. 1993, 49, 285-297. [CrossRef]

33. Jansson, H.-B.; Jeyaprakash, A.; Zuckerman, B.M. Differential Adhesion and Infection of Nematodes by the Endoparasitic Fungus Meria coniospora (Deuteromycetes). Appl. Environ. Microbiol. 1985, 49, 552-555.

34. Jansson, H.-B.; Nordbring-Hertz, B. Involvement of Sialic Acid in Nematode Chemotaxis and Infection by an Endoparasitic Nematophagous Fungus. Microbiology 1984, 130, 39-43. [CrossRef]

35. Dirksen, P.; Marsh, S.A.; Braker, I.; Heitland, N.; Wagner, S.; Nakad, R.; Mader, S.; Petersen, C.; Kowallik, V.; Rosenstiel, P.; et al. The native microbiome of the nematode Caenorhabditis elegans: gateway to a new host-microbiome model. BMC Boil. 2016, 14, 38. [CrossRef] [PubMed]

36. Köthe, M.; Antl, M.; Huber, B.; Stoecker, K.; Ebrecht, D.; Steinmetz, I.; Eberl, L. Killing of Caenorhabditis elegans by Burkholderia cepacia is controlled by the cep quorum-sensing system. Cell. Microbiol. 2003, 5, 343-351. [CrossRef] [PubMed]

37. Carta, L.K. Bacterial-Feeding Nematode Growth and Preference for Biocontrol Isolates of the Bacterium Burkholderia cepacia. J. Nematol. 2000, 32, 362-369. [PubMed]

38. Tahseen, Q.; Clark, I.M. Attraction and preference of bacteriophagous and plant-parasitic nematodes towards different types of soil bacteria. J. Hist. 2014, 48, 1485-1502. [CrossRef]

39. Ferris, H.; Bongers, T.; De Goede, R. A framework for soil food web diagnostics: extension of the nematode faunal analysis concept. Appl. Soil Ecol. 2001, 18, 13-29. [CrossRef]

40. Kitchen, S.; Ratnappan, R.; Han, S.; Leasure, C.; Grill, E.; Iqbal, Z.; Granger, O.; O’Halloran, D.M.; Hawdon, J.M. Isolation and characterization of a naturally occurring multidrug-resistant strain of the canine hookworm, Ancylostoma caninum. Int. J. Parasitol. 2019, 49, 397-406. [CrossRef]

41. Mamiya, Y.; Hiratsuka, M.; Murata, M. Ability of wood-decay fungi to prey on the pinewood nematode, Bursaphelenchus xylophilus (Steiner and Buhrer) Nickle. Jpn. J. Nematol. 2005, 35, 21-30. [CrossRef]

42. Renker, C.; Alphei, J.; Buscot, F. Soil nematodes associated with the mammal pathogenic fungal genus Malassezia (Basidiomycota: Ustilaginomoycetes) in Central European forests. Biol. Fertil. Soils 2003, 37, 70-72.

43. Platt, H.M. The Phylogenetic Systematics of Free-Living Nematodes; The Ray Society: London, UK, 1994.

(C) 2019 by the authors. Licensee MDPI, Basel, Switzerland. This article is an open access article distributed under the terms and conditions of the Creative Commons Attribution (CC BY) license (http://creativecommons.org/licenses/by/4.0/). 